\begin{tabular}{|c|l|}
\hline Title & Energy consumption and cost analysis of local parboiling processes \\
\hline Author(s) & Roy, Poritosh; Shimizu, Naoto; Shiina, Takeo; Kimura, Toshinori \\
\hline Citation & Journal of Food Engineering, 76(4), 646-655 \\
https://doi.org/40.1016/.joodeng.2005.06.034
\end{tabular}

Instructions for use 


\title{
Energy consumption and cost analysis of local parboiling processes
}

\author{
Poritosh Roy ${ }^{\text {a }}$, Naoto Shimizu ${ }^{\text {, }}$, Takeo Shiina ${ }^{a}$ and Toshinori Kimura ${ }^{\text {b,* }}$ \\ ${ }^{1}$ Distribution Engineering Laboratory, Food Engineering Division, National Food Research
}

Institute, Kannondai 2-1-12, Tsukuba 305-8642, Japan

${ }^{2}$ Graduate School of Life and Environmental Sciences, University of Tsukuba,

Tennodai 1-1-1, Tsukuba 305-8572, Japan

\begin{abstract}
This study was conducted at Gazole in the Malda district of West Bengal, India, by both the physical monitoring and questionnaire survey to evaluate the local parboiling processes (vessel, small-boiler and medium-boiler). The biomass consumption and head rice yield were measured and the market values were assessed by a questionnaire. The net present worth (NPW), payback period and internal rate of return were also determined. The parboiled rice produced under boiler processes had a higher market value compared to the vessel, but required a greater initial investment. The boiler processes were reported to be less tedious and provided a better working environment compared to the vessel. The head rice yield was estimated to be $65.9,69.2$ and $66.6 \%$ for the vessel, small-boiler and medium-boiler process, respectively. The medium-boiler consumed the lowest amount of energy (1659 MJ/t) compared to the others. The cost analysis of the parboiling processes revealed that all the
\end{abstract}


processes are economically viable, but the small-boiler was found to be the most attractive, having the shortest payback period and the highest internal rate of return. The local parboiling process can be improved in terms of the energy consumption and the market value of the rice by adopting the medium-boiler process.

Keywords: Local parboiling processes, Energy consumption, Cost analysis, Net present worth, Payback period, Internal rate of return

\footnotetext{
* Corresponding author. Tel.: 81-29-853-4650, fax: 81-29-855-2203, Email address: toshibio@sakura.cc.tsukuba.ac.jp (T. Kimura)
}

\section{Introduction}

Parboiling is an ancient method of rice processing and widely used in some developing countries including Bangladesh and India. It is a combined effort of soaking, steaming and drying. It was reported that one fourth of the world's paddy is parboiled (Kar, Jain \& Srivastab, 1999; Gariboldi, 1972), although it requires a considerable amount of energy and labor. Parboiled rice is produced by both traditional and modern processes. Modern processes are energy and capital intensive and are not suitable for small-scale operations at the village level. It is known that $90 \%$ of the paddy is parboiled in this region. In Bangladesh, more than $80 \%$ of the rice is processed in villages and less than $20 \%$ is processed in the commercial rice mills (Rahaman, Miah \& Ahmed, 1996) and the traditional 
parboiling processes are the most commonly used processes in the local areas (Roy, Shimizu, Furuichi \& Kimura, 2003a). In the modern parboiling process, the paddy undergoes hot soaking (at 55 to $70^{\circ} \mathrm{C}$ for 3 to $6 \mathrm{~h}$ ) before being steamed. Paddy or pre-steamed paddy is soaked ( 24 to $48 \mathrm{~h}$ ) with normal water before steaming in traditional parboiling process. Various parboiling methods and devices are being used for local parboiling. The device consists of pottery to boiler, used for direct or indirect heating, and consumes different amounts of energy.

Biomass often accounts for more than $90 \%$ of the total rural energy supplies in developing countries including Bangladesh and India (Bhattacharya, Abdul Salam \& Sharma, 2000). In Bangladesh, biomass resources are utilized to an extreme and possibly dangerous extent (Kennes, Parik \& Stolwisk, 1984). The combination of population growth with the decreasing per capita land area and growing needs of energy puts great stress on the available biomass resources (Bari, Hall, Lucas \& Hossain, 1998), and needs judicious alternation in the energy consumption pattern (Pokharel, Chandrashekar \& Robinson, 1992). Biomass combustion contributes as much as $20-50 \%$ of global green house gas emissions of which one third may come from households, which has an adverse effect on human health and the environment (Smith, 1999). The emission from biomass combustion depends on the quantities of fuels consumed and on the design of the combustion systems (Bhattacharya et al., 2000). Biomass used in the domestic sector has gained importance in the current global 
discussions on energy and environment in order to reduce deforestation and to conserve it (Gupta \& Ravindranath, 1997).

The eastern part of India (West Bengal) and Bangladesh share same parboiling processes and energy. Biomass, i.e., rice husk, is the main source of energy for local parboiling. Therefore, it is important to reduce the energy consumption in the local parboiling process to conserve biomass energy. The information on the energy consumption and cost of parboiling is limited and so far there has been no such study on the local parboiling processes. With the growing concern about the cost of parboiling, environmental pollution and health risks, a comparative study on the local parboiling processes is desired. This study attempts to evaluate the energy consumption and cost of local parboiling processes to determine a cost and energy effective parboiling process, which would be helpful to conserve biomass energy.

\section{Local production processes}

The production of parboiled rice is the main income source of many people in the local area. Various parboiling processes and devices are being used in the local parboiling

processes. The commonly used parboiling processes are vessel, small-boiler and the medium-boiler. Figure 1 shows the flow chart of the local parboiling processes. 


\subsection{Vessel process}

This process is considered to be a direct heating method of parboiling, used at the household level to produce parboiled rice for both their own consumption and commercial purposes having a little capital and no other income sources. All the adult members of the family are engaged in parboiling and it is done in the home yard. Parboiling is the main and only source of income for their daily life. Generally, the male persons are engaged in the buying and selling of paddy and rice, and also help in the parboiling process. The female members are responsible for both the parboiling and housekeeping.

The vessel is made of an aluminum sheet and the oven is made of clay or bricks and a clay mixer. One or two vessels are being used in this process (Fig. 2). A clay-pot (pottery), locally known as a char or masonry tank, is used for soaking. The use of a clay pot is reported to be tedious because soaked paddy needs to be elevated from the water and the excess water has to be manually drained. The masonry reservoir has a drain cock through which the excess soaked water is drained. The hand tube-well is the main source of water for this process. Water is also collected from a nearby pond, lake or river, having no tube-well. Vessel process is known to be more health hazardous and tedious compared to the others, because the people engaged in this process are directly exposed to smoke. Paddy is poured on the vessel and fires are lit underneath of it. A small amount of water is used during the pre-steaming, however, no water is used during the steaming treatment. The upper part of the paddy on the vessel turns 
to provide a uniform steaming treatment to the paddy mass. Loading and unloading is done manually with jars. The capacity of the vessel process varies from 0.5 to $1.2 \mathrm{t} / \mathrm{batch}$, depending on business capital.

\subsection{Small-boiler process}

This process is used for commercial purposes. Usually, the home yard is used as a drying yard, but if it is too small for use as a drying yard, separate places have also been used. Having a little business capital and processing capacity, all the adult family members are involved in this process. Sometimes, it is done on a contract basis. The owners are responsible to buy the paddy and sell the parboiled rice. The contracted people are responsible for the pre-steaming, soaking, steaming and drying. Payment is made per $100 \mathrm{~kg}$ of paddy.

One set of two conical hoppers made of aluminum sheets is used for the pre-steaming and steaming so that steam generation would be a continuous process and simultaneously applied to the paddy. Steam is generated in a boiler made from a used oil-barrel and applied to the paddy in the hoppers through connecting pipes (Fig. 3). A hand tube-well is the source for water. Steam flow is controlled by valves. No pressure gauge, water-meter or chimney are being used in this process, which provides poor safety measures and sometimes causes an accident. One masonry reservoir equipped with a drain cock is used for soaking. The people 
engaged in this process are also directly exposed to smoke and have a higher health risk. Paddy is manually loaded into the hoppers for pre-steaming and steaming using used oil-jars and unloaded by gravity. The capacity of this process varies from 2 to $4 \mathrm{t} / \mathrm{batch}$, depending on the business capital and on the drying yard area.

\subsection{Medium-boiler process}

This parboiling process is completely used for commercial purposes, having a separate yard other than the home yard (Fig. 4). The owners of this process are accountable for paddy buying, milling and selling of the rice. Paddy is supplied at the parboiling plant by some peoples engaged in the paddy business. One contractor is responsible for parboiling and payment is made per $100 \mathrm{~kg}$ of paddy. The contractor hires the people on a monthly or yearly basis for the parboiling activities.

Two sets of two conical hoppers are used for pre-steaming and steaming. The larger set is used for pre-steaming and the smaller set is used for the steaming treatment. Both sets are connected with a boiler through pipes and control valves. The hoppers are made of aluminum sheets and the boiler is made of mild-steel sheets. The boiler is equipped with a pressure gauge, water-meter and chimney. The pressure gauge and water-meter provides safety measures to the people working with it and the chimney keeps the smoke away from them, thus improving their working environment. Two concrete reservoirs equipped with a 
drain cock are used for soaking. Usually, a shallow tube-well is used to pump water into the boiler and soaking reservoir from a nearby pond. In this process, pre-steaming and steaming starts at the steam pressure of $245 \mathrm{kPa}$ and delivered to the paddy within the pressure range of 116 to $245 \mathrm{kPa}$. The paddy is manually loaded into the hoppers and unloaded it by gravity. The steamed paddy is unloaded into a three-wheeled trolley and taken to the drying yard. The capacity of this process varies from 5-10 t/batch.

\section{Materials and methods}

The study was conducted at Gazole in the Malda district of West Bengal, India, in 2000. West Bengal lies between latitude $20^{\circ} 31^{\prime}$ and $27^{\circ}-12^{\prime} \mathrm{N}$ and longitude $82^{\circ} \circ 50^{\prime}$ and $89^{\circ} 52^{\prime}$ E. Figure 5 shows the geographical location of this study area.

The local people who are involved in the parboiling business were contacted and asked for their cooperation to conduct this study. Among them, three persons were selected, who readily agreed to provide their assistance and be involved in the vessel (double-vessel), small-boiler (two-barrel) and medium-boiler processes of parboiling. The Sharna, a local variety of paddy, was used in all the parboiling processes. This study was conducted by both physical monitoring and a questionnaire survey. 


\subsection{Parboiling}

Pre-steaming: A pre-steaming treatment was done on the raw paddy for a short period to increase the paddy temperature which helps to increase the temperature of the soaking water and reduce the soaking time.

Soaking: Pre-steamed paddy was soaked overnight with an adequate amount of water. A nearby pond, river, lake or tube-well was the source of the water for parboiling. After draining the excess soaking water, the soaked paddy was steamed.

Steaming: The soaked paddy was then allowed to steam in different tally. The pre-steaming and the steaming time for each tally was recorded for all processes. The pre-steaming and steaming treatments were assumed to be complete when the steam started coming out from all over the paddy mass surface in the vessels or hoppers. The parboiled paddy was then moved to the drying yard, heaped for a few minutes for steeping before spreading for drying.

Drying: Sun drying is the common practice in the local parboiling processes, and was used on the parboiled paddy on the compacted earth floor. It took 1-2 days or more depending on the weather.

\subsection{Head rice yield}

Head rice yield is an estimate of the quantity of head rice which can be produced 
from a unit of paddy. The parboiled paddy produced in all the processes was milled at an automatic rice milling plant (Radha Gobindo Rice Mill, Gazole: V-belt dehusker, rice Cone Polisher \& JM King Mini Machine) to homogenize the milling treatment and the degree of milling. The head rice yield was calculated with respect to the paddy weight and it was expressed as a percentage.

\subsection{Energy consumption}

Biomass (rice husk) is the only or main source of energy for the local parboiling processes, which is a byproduct of the rice processing industry. In this study, only the biomass energy consumption during pre-steaming and steaming was measured. No energy is used during the soaking treatment, but the heat energy is lost. Sun drying is the common practice in the local parboiling processes. Therefore, the energy consumption during drying was not considered. To measure the energy consumption in the local parboiling processes, the mass of a sufficient amount of rice husk was measured before each treatment of a paddy batch. A local type of balance was used to measure the mass of the rice husk and paddy in $\mathrm{kg}$ (Fig. 6). Also, an additional amount of rice husk was kept nearby as a standby source. After each treatment, the mass of the excess rice husk was measured. The rice husk consumed for a particular treatment was calculated by subtracting the final mass from the initial mass. The amount of paddy parboiled in a batch was recorded in the same way that was used to measure 
the biomass consumption. Finally, the amount of rice husk consumption in the parboiling process of a paddy batch was calculated and expressed in $\mathrm{MJ} / \mathrm{t}$. A very small amount of straw was used for the initial firing in all processes which was negligible compared to the husk consumed in the process and was not considered as a part of the energy consumption.

\subsection{Cost analysis of local parboiling processes}

The life of the equipment used in the parboiling processes varies and the market price of the paddy, rice and husk fluctuates over time. Therefore, a cost analysis was performed based on the following assumptions: i) life span of the parboiling processes is 10 years, ii) salvage value is $10 \%$ of the initial installation cost, iii) the parboiling intensity is 15 batch/month, iv) the return on investment i.e., profit, was calculated on a monthly basis, v) the payback period was calculated on the equal profit for months of operations, vi) the business capital was equivalent to the value of three paddy batches of the respective process, vii) the capacity of the vessel, small-boiler and medium-boiler was 1150,3500 and 10000 $\mathrm{kg} / \mathrm{batch}$, respectively, and viii) no fluctuation in prices. The interest rate in the region (India and Bangladesh) varies from 10 to $20 \%$, thus this analysis was performed for the interest rate of 10,15 and $20 \%$.

Husk, bran and broken grains are the byproducts of the rice processing industry. The amount of byproducts varies with the variety of paddy. The long grains produce $22-24 \%$ husk 
of the paddy mass (Harry, 1985). The production of rice bran depends upon the degree of milling, i.e., whitening. Generally, it accounts for 5-8\% of the paddy mass (Juliano, 1985). Most of the milling facilities in the local area produce a byproduct as a mixture of the husk, bran and broken grains, used as fuel for the parboiling. In this study, the husk and bran were assumed to be $22 \%$ and $7 \%$ of the paddy mass, respectively. Therefore, the total biomass (husk+bran) production was considered to be $29 \%$ of the paddy mass.

The cost related data were collected in the local currency (rupee) and expressed it in US\$ ( 1 US\$ = 47 Rupee). The fuel cost of the shallow tube-well was reported to be US\$ $10.6 /$ month. The benefit or monthly return of the processes was calculated using the respective field data. It was calculated from the difference in the output (parboiled rice \& husk) and the input (paddy, used husk \& other fuel cost) amount of money in the process. The benefit of the parboiling processes was calculated using the following equation (Eq. 1).

$$
B=(V P R+V H)-(V P+M C+P C+V U H+F C T) \quad . \quad \text { Eq. } 1
$$

where $\mathrm{B}=$ benefits, $\mathrm{VPR}=$ value of parboiled rice, $\mathrm{VH}=$ value of husk, $\mathrm{VP}=$ value of paddy, $\mathrm{MC}=$ milling cost, $\mathrm{PC}=$ parboiling cost, $\mathrm{VUH}=$ value of used husk, $\mathrm{FCT}=$ fuel cost for tube-well.

The present values of the negative and positive cash flows were calculated using the following equation.

$$
P=F\left(\frac{1}{1+i}\right)^{n}
$$


where, $\mathrm{P}=$ present value of the negative (investment cost $\&$ business capital in the beginning) or positive (benefits \& capital at the end) cash flows of the process, $\mathrm{F}=$ future investment or return of the process, $\mathrm{i}=$ interest rate per year, $($ decimal), and $\mathrm{n}=$ number of interest periods, year.

The cost and profit of the parboiling process was calculated based on the present value of all the investment and benefits from the process. The straight-line depreciation method was used to calculate the depreciation of the parboiling process and deducted from the monthly benefit to determine the monthly profit. The net present worth (NPW), payback period and internal rate of return (IRR) were calculated to measure the economic viability of the processes and compared to determine the suitable process. The NPW of the process was calculated from the difference between the sum of the present value of the positive and negative cash flows of the process.

$$
\mathrm{NPW}=\sum \mathrm{P}_{\mathrm{p}}-\sum \mathrm{P}_{\mathrm{n}} \quad \cdot \quad \cdot \quad \cdot \quad \text { Eq. } 3
$$

where, $P_{p}=$ Present value of positive cash flow, and $P_{n}=$ Present value of negative cash flow.

The payback period was calculated from the following relationship.

$$
\text { Payback Period }=\frac{\text { Sum of } \mathrm{P}_{\mathrm{n}}}{\text { Monthly Profit }} \quad . \quad \ldots \quad . \quad \text { Eq. } 4
$$




\section{Results and discussion}

\subsection{Parboiling}

Both the direct and indirect heating methods are being used in the local area to produce parboiled rice. The vessel and the boiler processes are considered to be a direct and indirect heating process, respectively. In this study, both the physical monitoring and questionnaire survey revealed important findings about the local parboiling processes. All the adult family members are engaged in the vessel process, having a little capital and no other income sources. In the small-boiler process, it is done either by the family member or on a contract basis depending on the business capital and capacity. The hired or contracted people are responsible for parboiling in the medium-boiler process. The boiler processes were reported to be less tedious and improves the labor efficiency.

The treatments time varied from process to process. The steam generation in the parboiling processes seems to be dependent on the firing intensity and the skill of the person involved in the firing operation. For this reason, the treatment time for different tally varied and another reason might be the steam flow rate. The pre-steaming and steaming was assumed to be complete when the excess steam started to come out all over the paddy mass surface. The average pre-steaming and steaming times per tally were the highest for the 
vessel process and lowest for the medium-boiler process. Table 1 shows the average treatment times and parboiling capacity per person per batch. No initial firing is required for the vessel process because the paddy is poured on the vessel and firing starts. The pre-steaming and steaming is started when the steam starts coming out from the pipe and at a pressure of $245 \mathrm{kPa}$ for the small boiler and medium boiler processes.

\subsection{Head rice yield}

The parboiling treatment gelatinizes the rice starch, improves the hardness of the rice, minimized the breakage loss and consequently increases the milling yield (Gariboldi, 1974; Kimura, Shimizu, Shimohara \& Wsrashina, 1995; Roy, Shimizu \& Kimura, 2000; Islam, Roy, Shimizu \& Kimura, 2002). The quality of the paddy, intensity of parboiling and degree of milling also affect the milling yield. The color and lightness of the rice are also closely affected by the material temperature and the degree of parboiling (Bhattacharya \& Rao, 1966; Kimura, Bhattacharya \& Ali, 1993; Roy, Shimizu \& Kimura, 2004). Over-parboiling resulted in over-opening of the husk components followed by bulging out of the endosperm which initiates surface scouring during milling and the resultant ground particles being lost into the husk and bran. On the other hand, incomplete or non-uniform parboiling produce white-bellied rice, which breaks easily during milling, and reduces the head rice yield (Sarker \& Faruk, 1989). It has been reported that the head rice yield is also affected by the drying 
condition and moisture content after drying. The head rice yield is estimated to be 65.9, 69.2 and $66.6 \%$ for the vessel, small-boiler and medium-boiler, respectively. The difference in the other quality indicators (hardness, color intensity, lightness value and moisture content) of the rice produced by the local parboiling processes was reported to be insignificant (Roy, Shimizu \& Kimura 2003b; Roy, 2003). In this study, the paddy parboiled by the different processes was not from the same lot, which might also affect the yield of the respective processes. The parboiled rice produced in the boiler processes is considered to be suitable and better because it has greater customer acceptance and market value.

\subsection{Energy consumption}

The energy consumption varied from process to process. It increased with an increase in the treatments time. In this study, the energy consumption and treatment time were found to be higher for the steaming compared to the pre-steaming. The energy consumption was the lowest in the medium-boiler process and highest for the small-boiler. It was slightly higher in the small-boiler process compared to the vessel. The energy consumption was found to be lower than the boilerless parboiling (4200 MJ/t), where hot soaking was done to the paddy and considered to be a modern method (Tiwary \& Ojha, 1981). The energy consumption in the laboratory-scale traditional parboiling was 1400-2442 MJ/t and depended on the treatments time (Roy et al., 2003a). The medium-boiler consumed a lower amount of energy, 
but the small-boiler and vessel consumed a higher amount of energy than the laboratory-scale traditional parboiling, possibly because of the type of energy and equipment. Table 2 shows the energy consumption during the different treatments of the parboiling processes in this study.

The small-boiler process was found to be an energy intensive process compared to the vessel and medium-boiler, perhaps because of the use of a two-barrel boiler seemed responsible for the loss of heat energy through the gap between the barrels during the parboiling. The medium-boiler is equipped with a pressure gauge and a water-meter, but the small-boiler has no pressure gauge and water-meter which helps to maintain the required amount of water for the specific treatments, thus leading to energy savings. The initial firing time of the small-boiler process clearly indicates the inefficient utilization of heat energy during the pre-steaming, causing a higher energy consumption. Another reason might be the high ambitious boiler installation and lower amount of paddy parboiled due to lack of capital and a limited drying yard.

\subsection{Cost analysis}

The cost and profit are the most important factors in decision making for an investment. The installation of the parboiling facilities consists of different parts and the cost depends on the price of the respective parts and their economic life. The cost of land used in 
the parboiling processes was not included in the cost analysis because the land price is reported to be same per tonne of production capacity. The price of the respective parts and their useful life is shown in Table 3. The market price of paddy, rice and husk, costs of parboiling (labor) and milling were collected through a questionnaire survey and were reported in Table 4. The boiler processes needs a higher initial installation cost and investment compared to the vessel.

The negative positive and cash flows represent the investment and return on investment, respectively. The negative and positive cash flows in the parboiling processes are graphically shown for the life period (Fig. 7). The NPW was found to be the highest for the medium-boiler and the lowest for the vessel process. It decreases with the gradual increase in the interest rate for all the processes. The payback period was found to be the longest for vessel and shortest for the small-boiler process. The value of the NPW shows that all the processes are economically viable, but the medium-boiler process was found to be more attractive than the others but required a greater investment. Figure 8 shows the NPW at different interest rates and Fig. 9 shows the payback period of the parboiling processes.

The IRR is the interest rate at which the NPW becomes zero i.e., the value where the curves cross the i-axis (Fig. 10). The value of IRR was worked out using the linear interpolation of the interest rate and the NPW. Although the NPW was the highest for medium-boiler process, but the payback period was higher than that of the small-boiler. The 
IRR was the highest for the small-boiler process and lowest for the vessel. It was 491.7, 5794.0 and $2946.4 \%$, respectively, for the vessel, small-boiler and medium-boiler process. The cost analysis of the parboiling processes revealed that all the processes are economically viable but the small-boiler was found to be the most attractive, having the shortest payback period and the highest internal rate of return compared to the others. Considering the uncertainty of the investment and the limitation of business capital, the small-boiler process seems to be the best choice for the local people, although it consumes a slightly higher amount of energy than the vessel and the medium-boiler. Therefore, it would be wise to produce parboiled rice with an improved small-boiler which could be the most cost and energy effective process.

\section{Conclusions}

The small-boiler process consumed the highest amount of energy while the lowest was the medium-boiler. The rice produced in the boiler processes has a higher customer acceptance and market value than that of the vessel process. The boiler process reduces the processing time (pre-steaming and steaming), however, it requires a greater investment and installation cost. All the processes were economically viable but the small-boiler is found to be the most attractive because of its lowest payback period and highest internal rate of return compared to the others. Considering the uncertainty on the investment, it would be wise to 
produce parboiled rice by adopting an improved small-boiler which could be the highest cost and energy effective process in the local area. This study revealed that the substitution of the parboiling process not only conserves biomass energy, but also reduces the processing time. A nominal incentive to install the boiler process, motivation and awareness of the environment and health are required for method switching. The method switching would reduce the production costs, improve the local parboiling process in terms of energy consumption and market value of the rice, and lead to reducing the environmental pollution and deforestation in the local area.

\section{Acknowledgement:}

The authors would like to express their sincere thanks to Mr. Jagodish Roy (Radha

Gobindo Rice Mill, Gazole), Mr. Jogendra Mandal, Mr. Subal Skarker and Mr. Tarun Kumar Roy for their assistance during this study.

\section{References}

Bari, M.N., Hall, D.O., Lucas, N.J.D., \& Hossain, S.M.A. (1998). Biomass energy use at the household level in two villages of Bangladesh: assessment of field methods. Bimass and Bioenergy, 15(2), 171-180.

Bhattacharya, K.R., \& Rao, S.P.V. (1966). Effect of processing conditions on quality of 
parboiled rice. Journal of Agricultural and Food Chemistry, 44, 592-600.

Bhattacharya, S.C., Abdul Salam, P. \& Sharma, M. (2000). Emission from biomass energy use in some selected Asian countries. Energy, 25, 169-188.

FAO (1997). Energy and environment basics. Regional Wood Energy Development Programme in Asia, Food and Agricultural Organization of the United Nations, RWEDP Report No. 29.

Gariboldi, F. (1972). Parboiled rice, Rice Chemistry and Technology (1 ${ }^{\text {st }}$ ed., pp. 358-380). American Association of Cereal Chemists, Inc. St. Paul, Minnesota, USA.

Gariboldi, F. (1974). Rice parboiling. Food and Agriculture Organization of the United Nations, Rome, Italy.

Gupta, S., \& Ravindranath, N.H. (1997). Financial analysis of cooking energy options for India. Energy Conversion and Management, 38(18), 1869-1876.

Harry, T.L.van Ruiten (1985). Rice milling: an overview. Rice Chemistry and Technology (2 $2^{\text {nd }}$ ed., pp. 349-388). American Association of Cereal Chemists, Inc. St. Paul, Minnesota, USA.

Islam, R., Roy, P., Shimizu, N., \& Kimura, T. (2002). Effect of processing conditions on the physical properties of parboiled rice. Food Science and Technology Research, 8(2), 106-112.

Juliano, B.O. (1985). Rice bran. In Rice Chemistry and Technology (2 ${ }^{\text {nd }}$ ed., pp. 647-687) American Association of Cereal Chemists, Inc. St. Paul, Minnesota, USA.

Kar, N., Jain, R.K., \& Srivastav, P.P. (1999). Parboiling of dehusked rice. Journal of Food 
Engineering, 39, 17-22.

Kennes, W., Parik, J.K., \& Stolwisk, H. (1984). Energy from biomass by socio-economic groups? a case study of Bangladesh. Biomass, 4, 209-234.

Kimura, T., Bhattacharya, K.R., \& Ali, S.Z. (1993). Discoloration characteristics of rice during parboiling (I): Effect of processing conditions on the color intensity of parboiled rice. Journal of the Japanese Society of Agricultural Structure, Japan, 22, 111-116.

Kimura, T., Shimuzu, N., Shimohara, T., \& Wsrashina, J. (1995). Trials of ouality evaluation for parboiled and other rice by means of the near infrared spectroscopy and the rapid visco analyzer. Journal of the Society of Agricultural Structures, Japan, 25(4), 175-181.

Pokharel, S., Chandrashekar, M., \& Robinson, J.B. (1992). Interfuel and intermode substitution for cooking. Energy, 17(10), 907-918.

Rahaman, M.A., Miah, M.A.K., \& Ahmed, A. (1996). Status of rice processing technology in Bangladesh, Journal of Agricultural Mechanization in Asia, Africa and Latin America, 27(1), 46-50.

Roy, P., Shimizu, N., \& Kimura, T. (2000). Measurement of energy requirement in traditional parboiling process, In Proceedings of the Association of Asian Agricultural Engineers, Asian Institute of Technology, Pathumthani, Thailand.

Roy, P., Shimizu, N., Furuichi, S., \& Kimura, T. (2003a). Improvement of traditional parboiling process. Journal of the Japanese Society of Agricultural Machinery, 65(1), 159-166. 
Roy, P., Shimizu, N., \& Kimura, T. (2003b). Energy consumption in local parboiling processes. Journal of the Japanese Society of Agricultural Machinery, 65(5), 133-141.

Roy, P., 2003. Improvement of energy requirement in traditional parboiling process. PhD Thesis, University of Tsukuba (unpublished).

Roy, P., Shimizu, N., \& Kimura, T. (2004). Effect of temperature distribution on the quality of parboiled rice produced by traditional parboiling process. Food Science and Technology Research, 10 (3), in press.

Sarker, N.N., \& Farouk, S.M. (1989). Some factors causing milling loss in Bangladesh. Journal of Agricultural Mechanization in Asia, Africa and Latin America, 20(2), 49-56.

Smith, K.R. (1999). Fuel emission, health and global warming. Regional Wood Energy Development Programme in Asia (FAO). Wood Energy News, 14(3), 4-5.

Tiwary, T., \& Ojha, T.P. (1981). Performance of boilerless parboiling system. Journal of Agricultural Mechanization in Asia, Africa and Latin America, Winter, 60-62. 


\section{List of Figures and Tables}

\section{Figures:}

Fig. 1 Flow chart of the local parboiling processes

Fig. 2 Vessel process of parboiling

Fig. 3 Small-boiler process of parboiling

Fig. 4 Medium-boiler process parboiling

Fig. 5 Map of West Bengal and the location of the study area

Fig. 6 A local type balance used to measure the mass of paddy and husk

Fig. 7 Cash flow diagrams of the parboiling processes (US\$)

(Note: S.V. = salvage value)

Fig. 8 Comparison of the NPW of the parboiling processes at different interest rate

Fig. 9 Comparison of the payback period of parboiling processes at different interest rate

Fig. 10 Relationship between interest rate and the NPW of future income

\section{Tables:}

Table 1 Treatments time and parboiling capacity

Table 2 Energy consumption in the parboiling processes

Table 3 Installation costs of the parboiling plants (US\$)

Table 4 Cost of labor for parboiling, milling and the market price of paddy, parboiled rice and rice husk (US\$) 


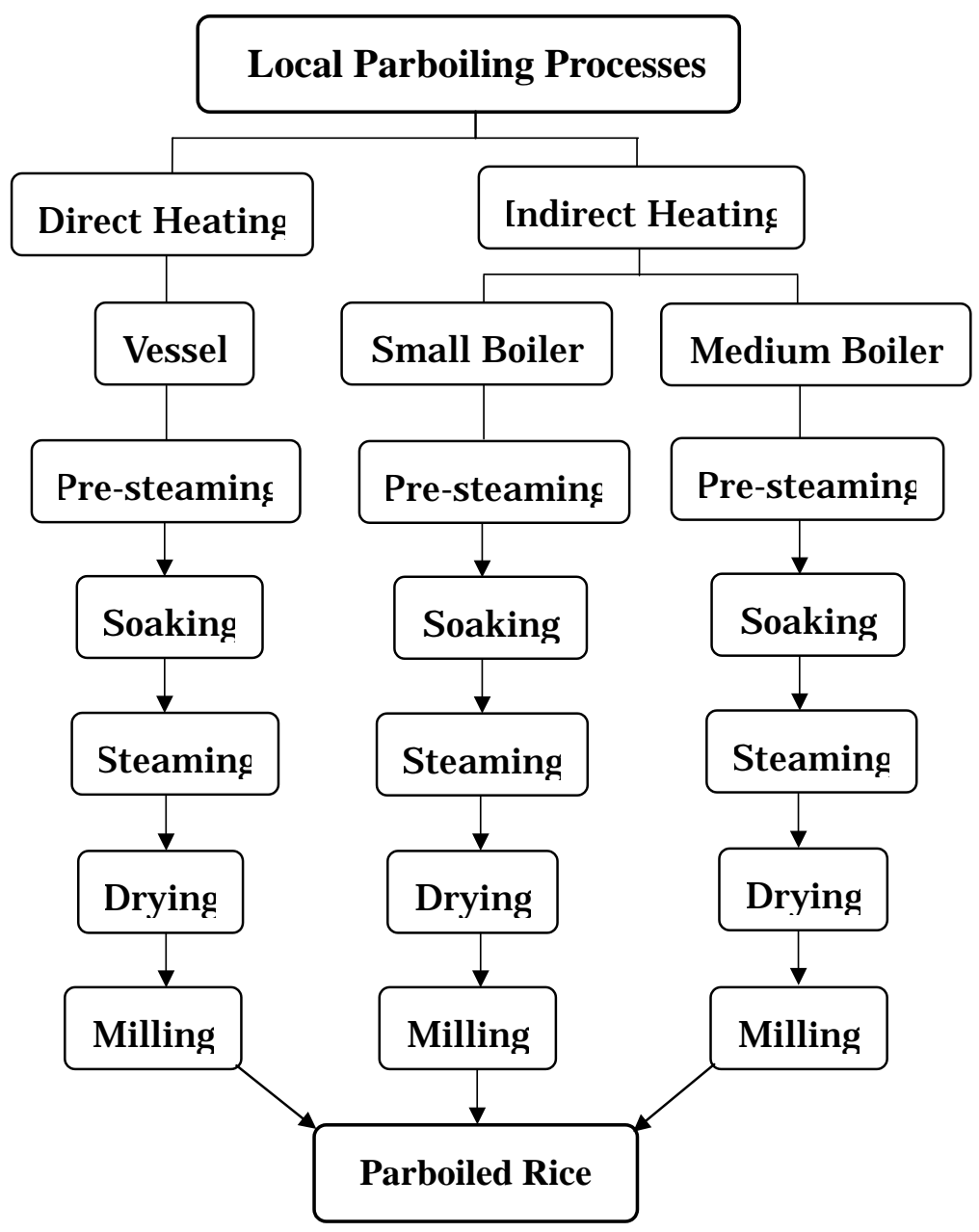

Fig. 1 Flow chart of the local parboiling processes 


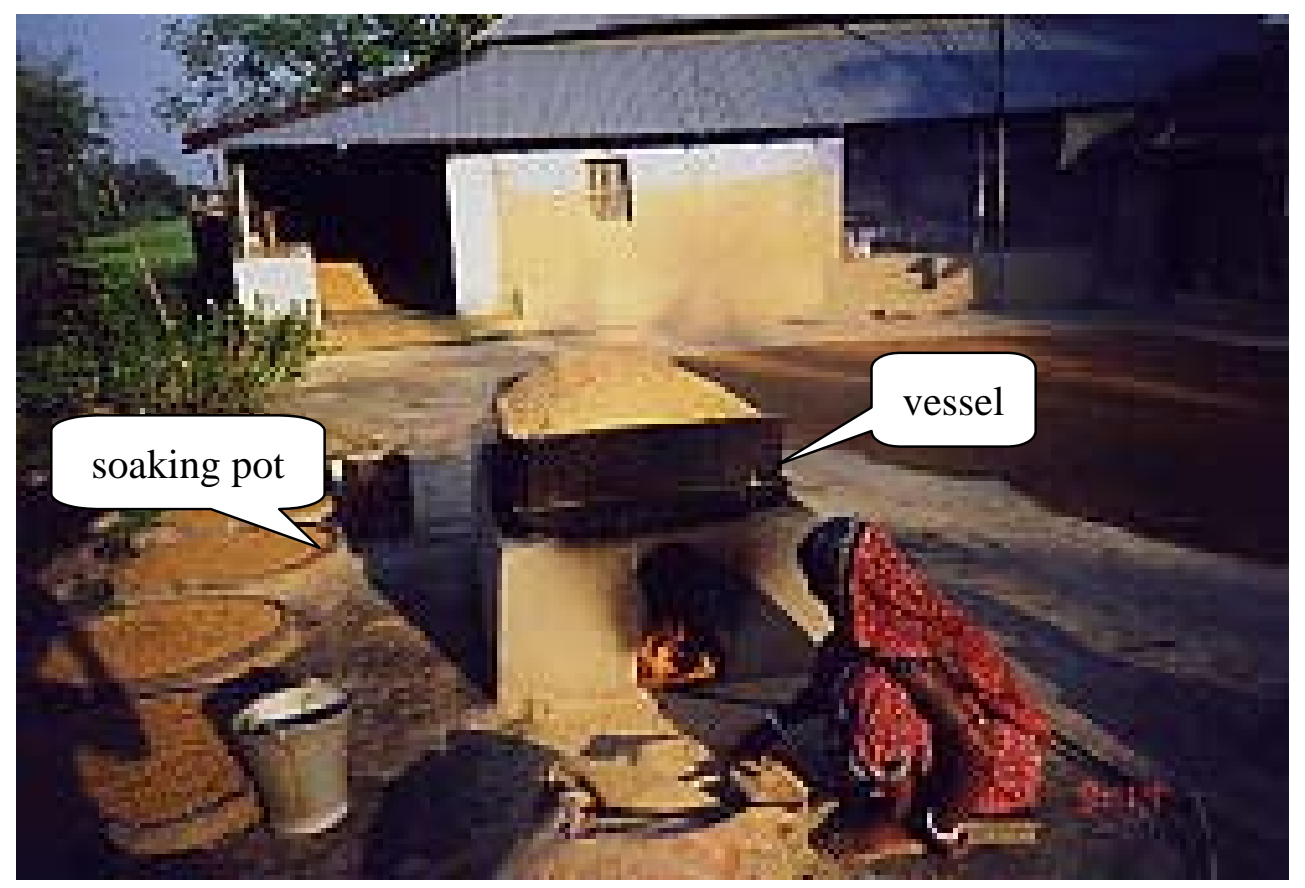

a. Single vessel

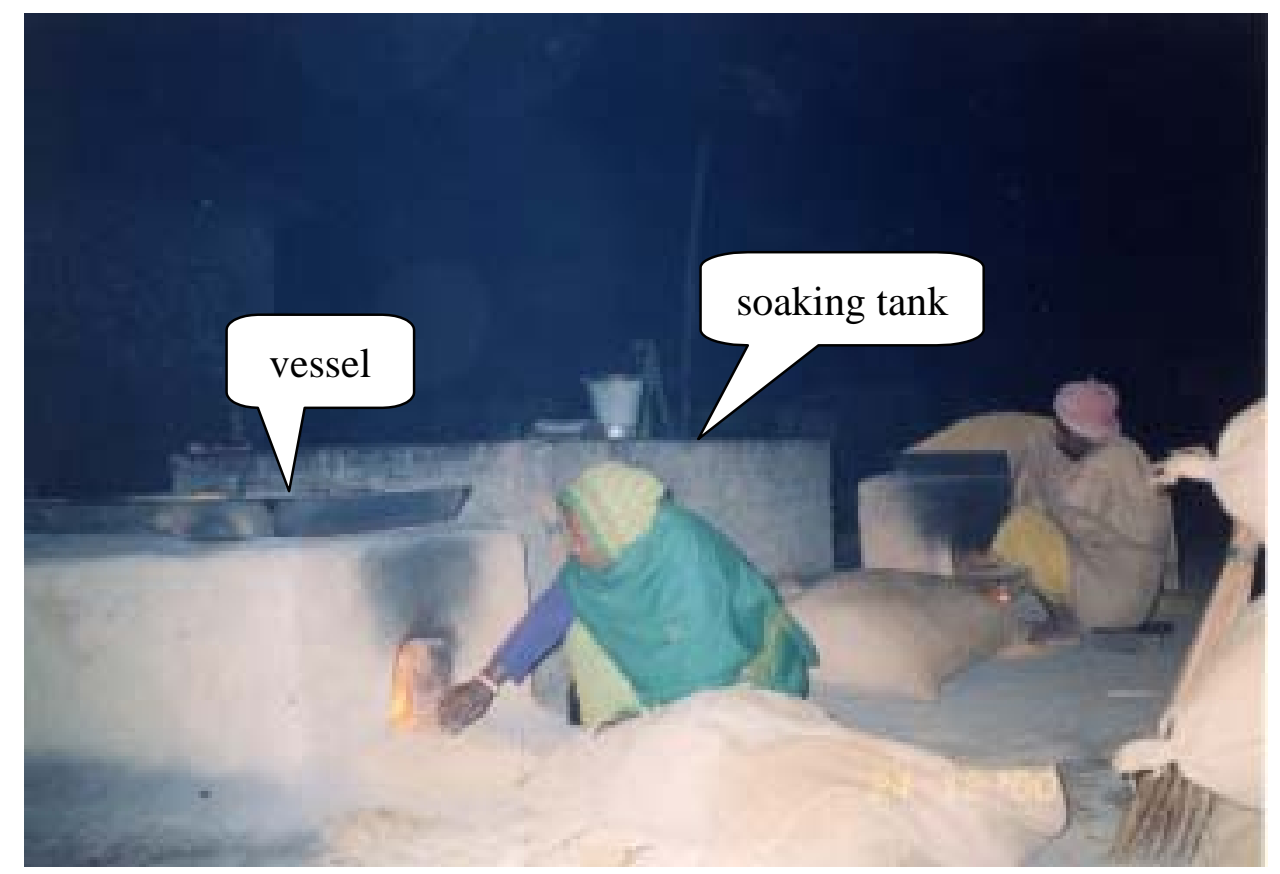

b. Double vessel

Fig. 2 Vessel process of parboiling 


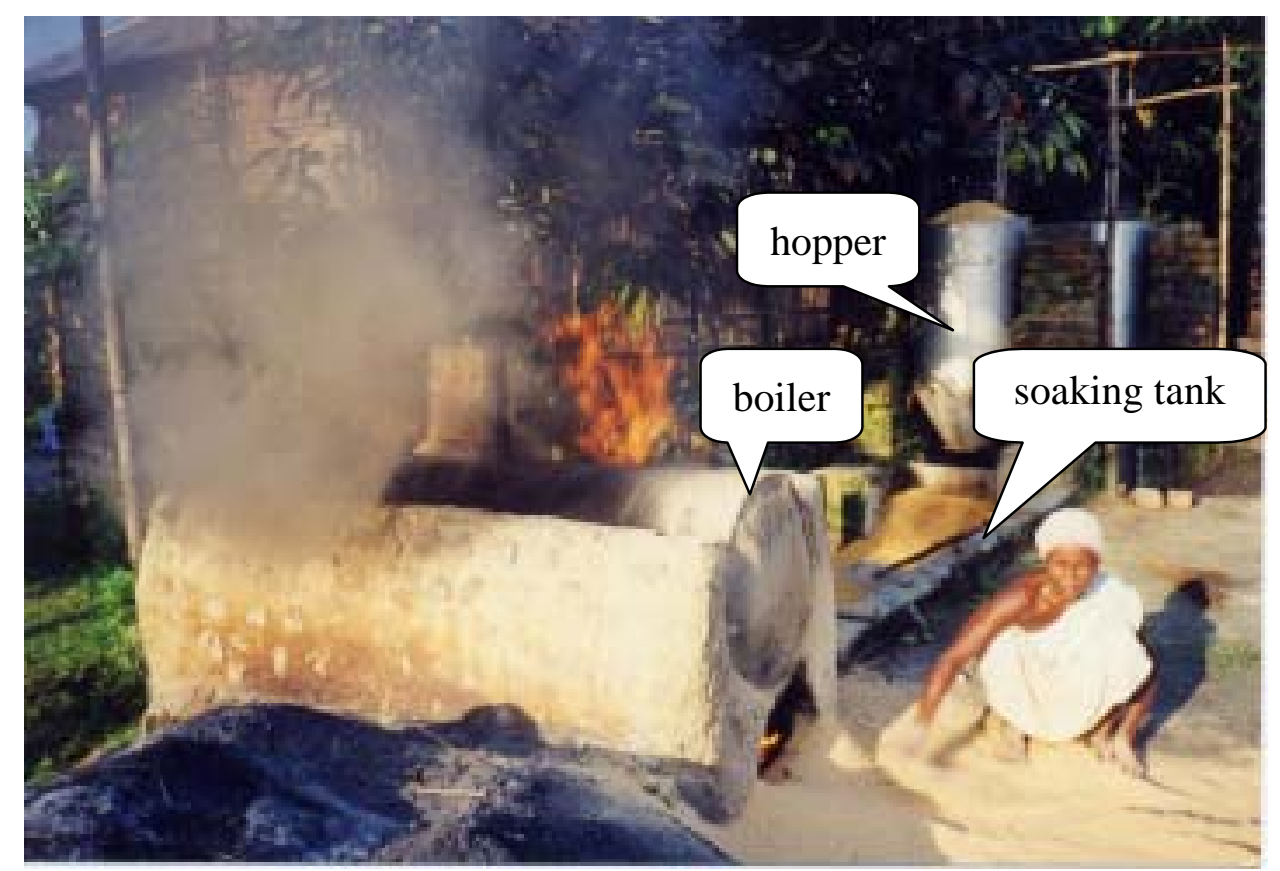

a. Single barrel-boiler

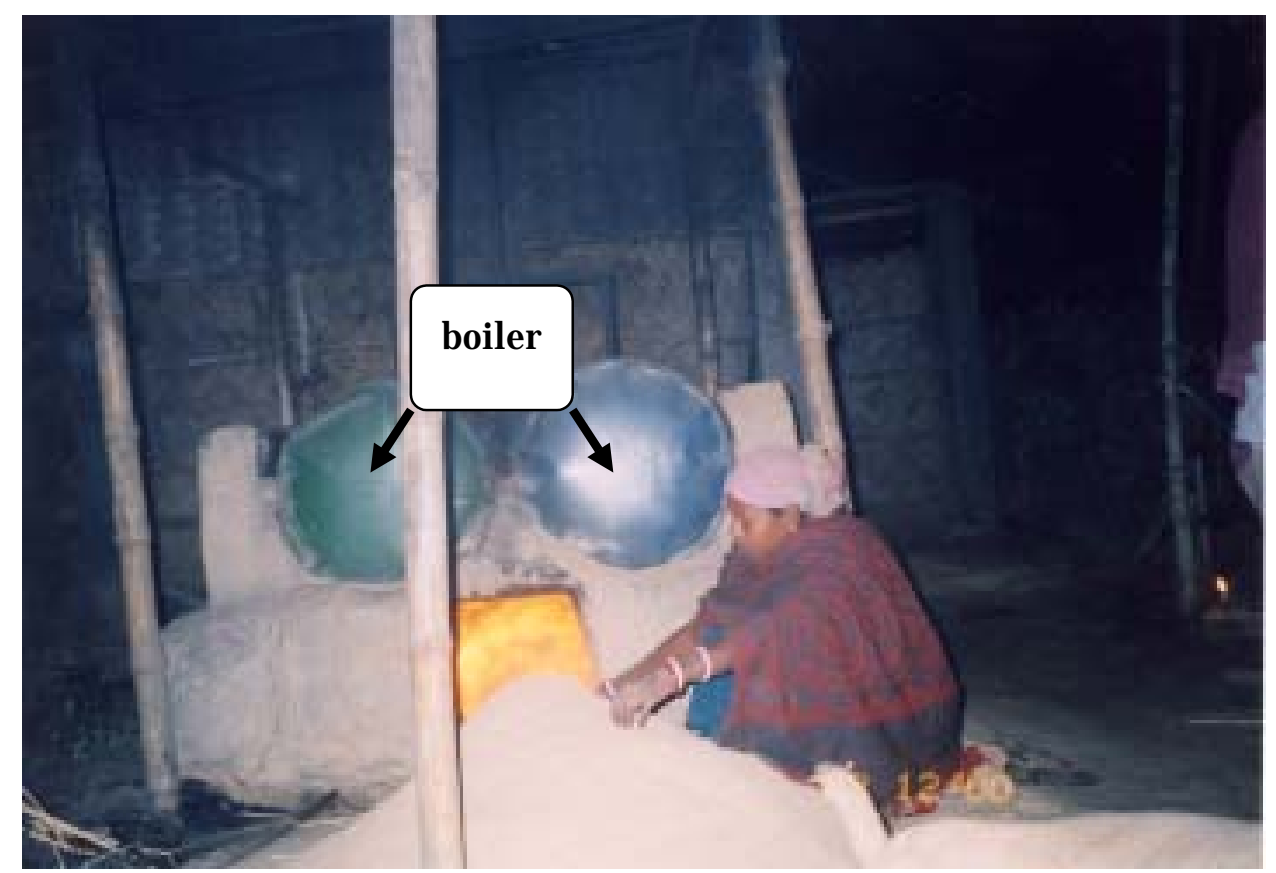

b. Double barrel-boiler

Fig. 3 Small-boiler process of parboiling 


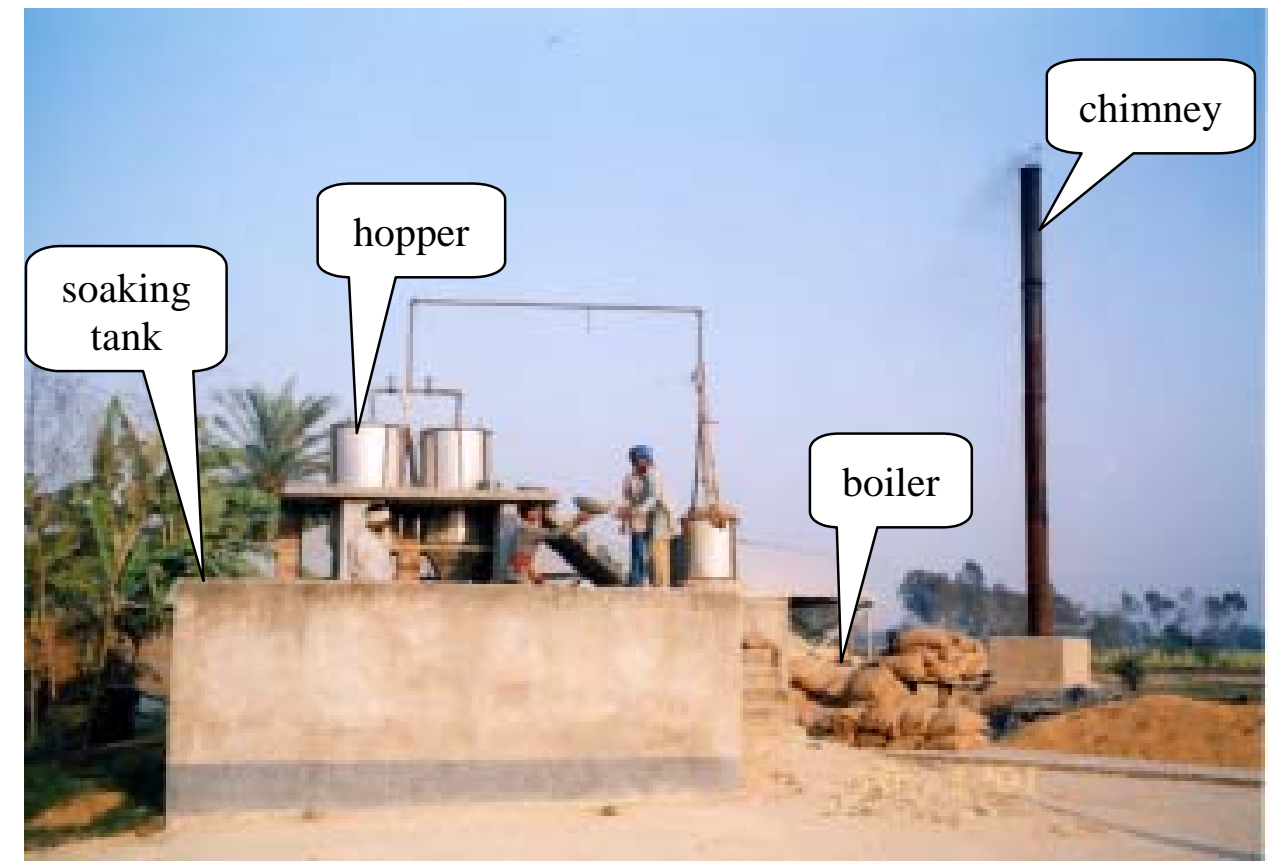

Fig. 4 Medium-boiler process of parboiling 


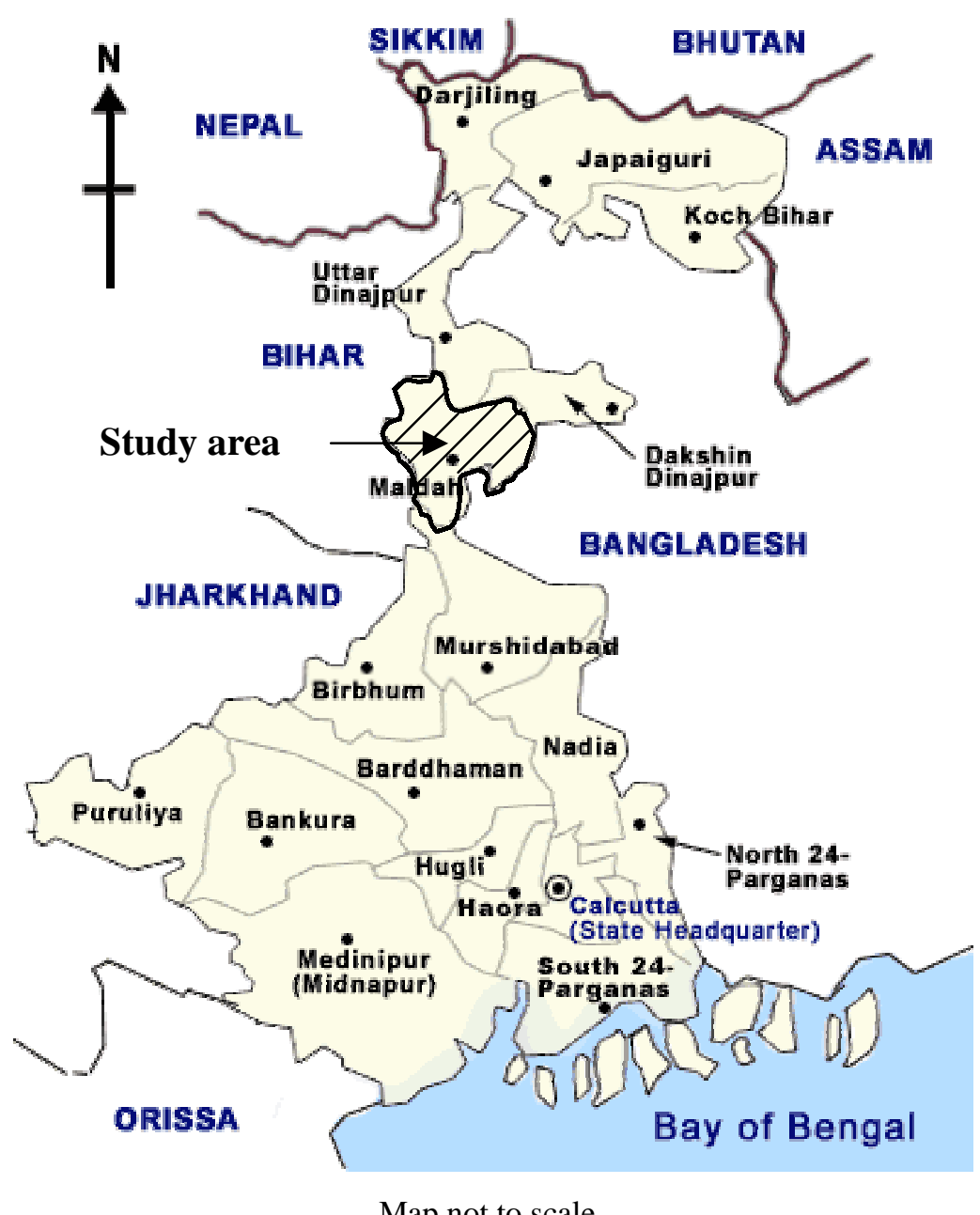

Map not to scale

Fig. 5 Map of West Bengal and the location of the study area 


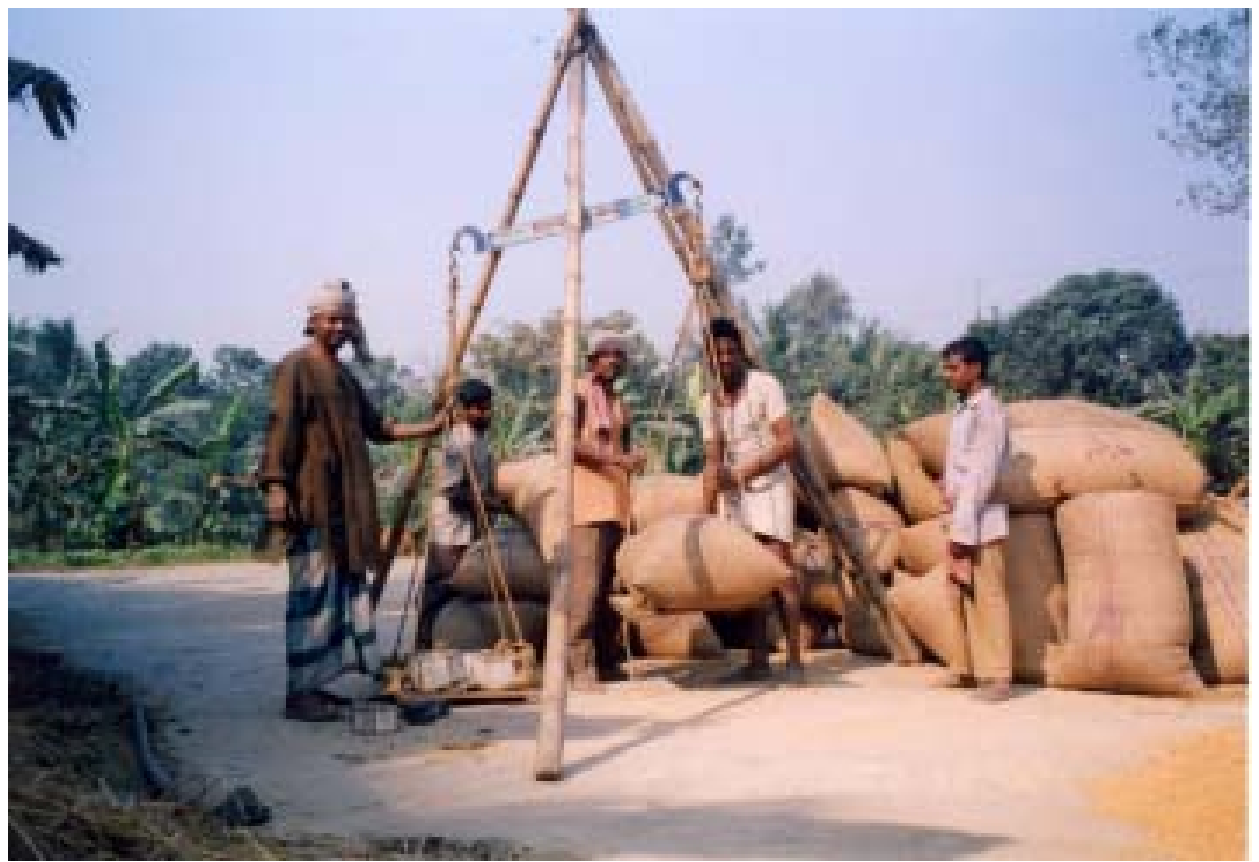

Fig. 6 A local-type balance used to measure the mass of paddy and husk 


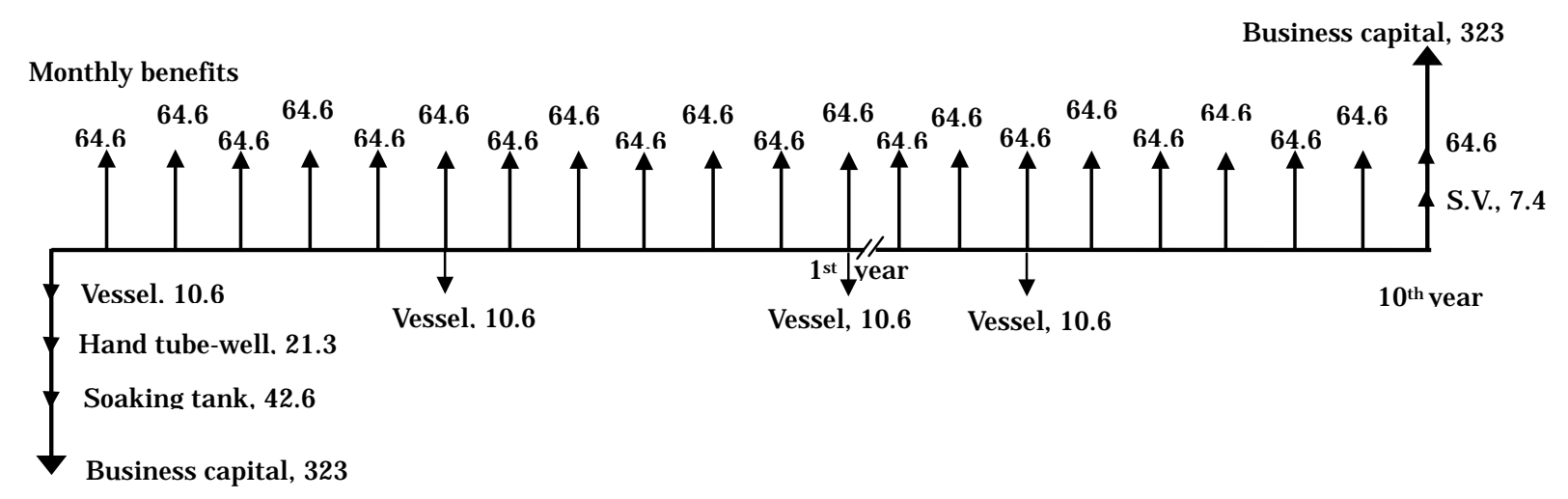

a. Vessel

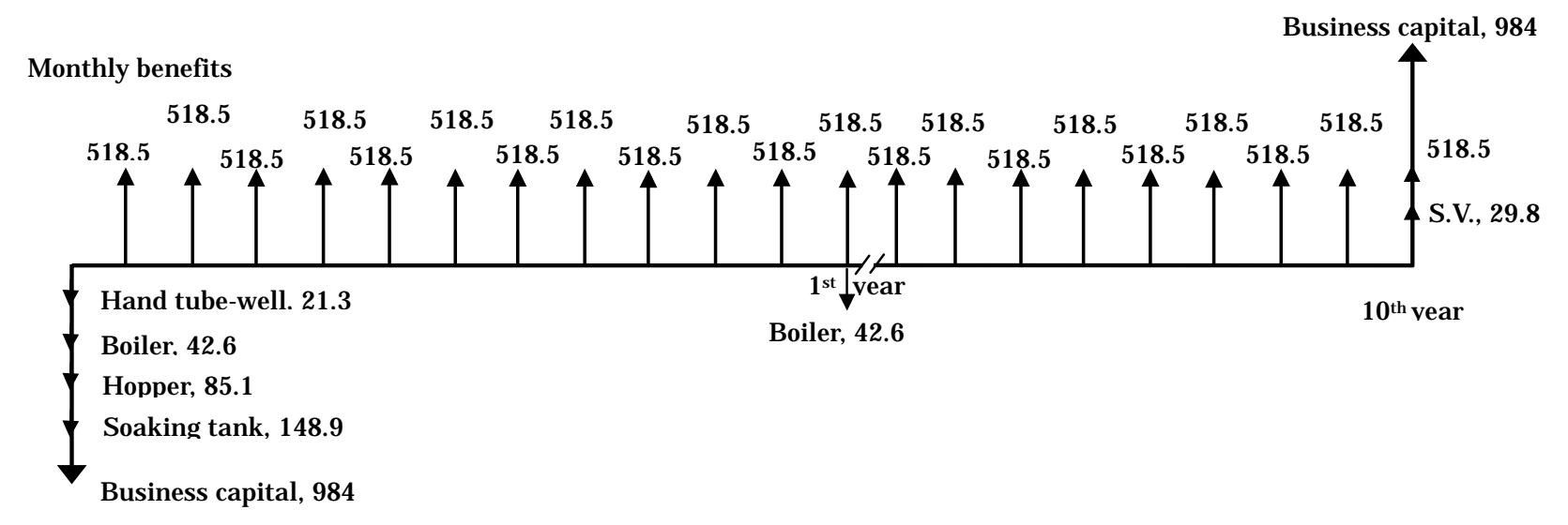

b. Small-boiler

Business capital, 2824.5

Monthly benefits

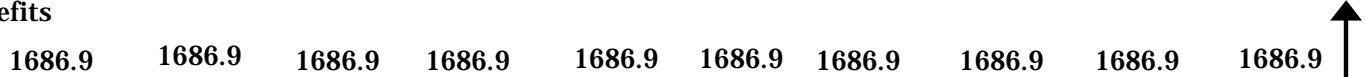

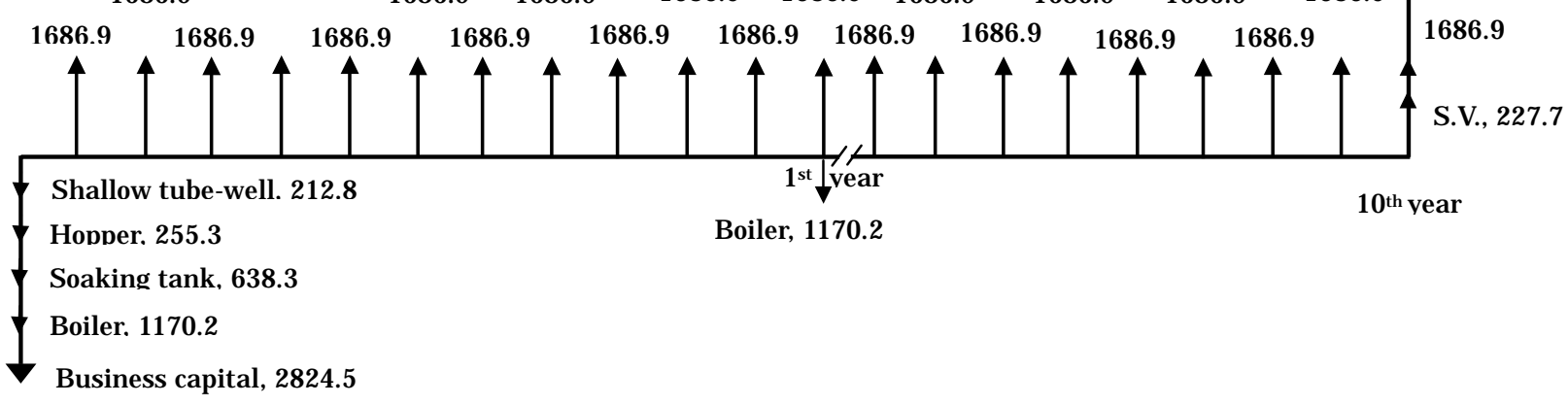

c. Medium-boiler

Fig. 7 Cash flow diagrams of the parboiling processes (US\$)

(Note: S.V. = salvage value) 


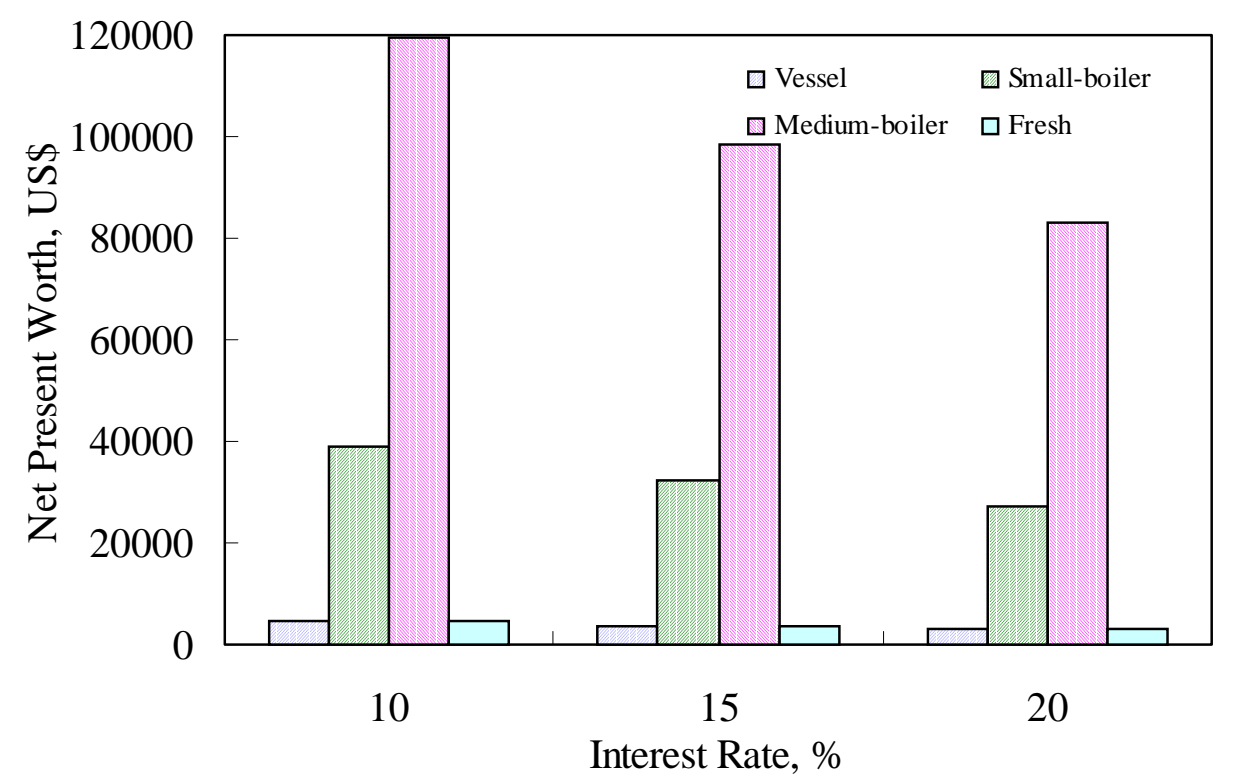

Fig. 8 Comparison of the NPW of the parboiling processes at different interest rate

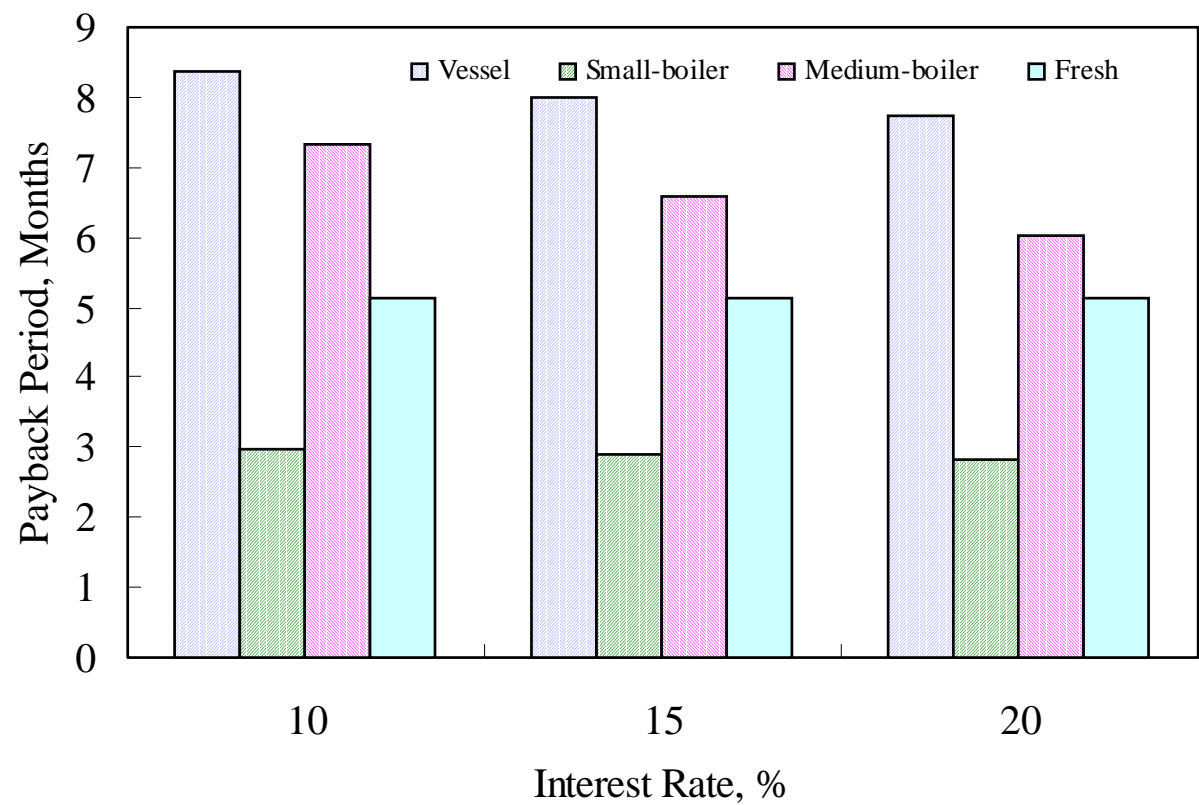

Fig. 9 Comparison of the payback period of parboiling processes at different 

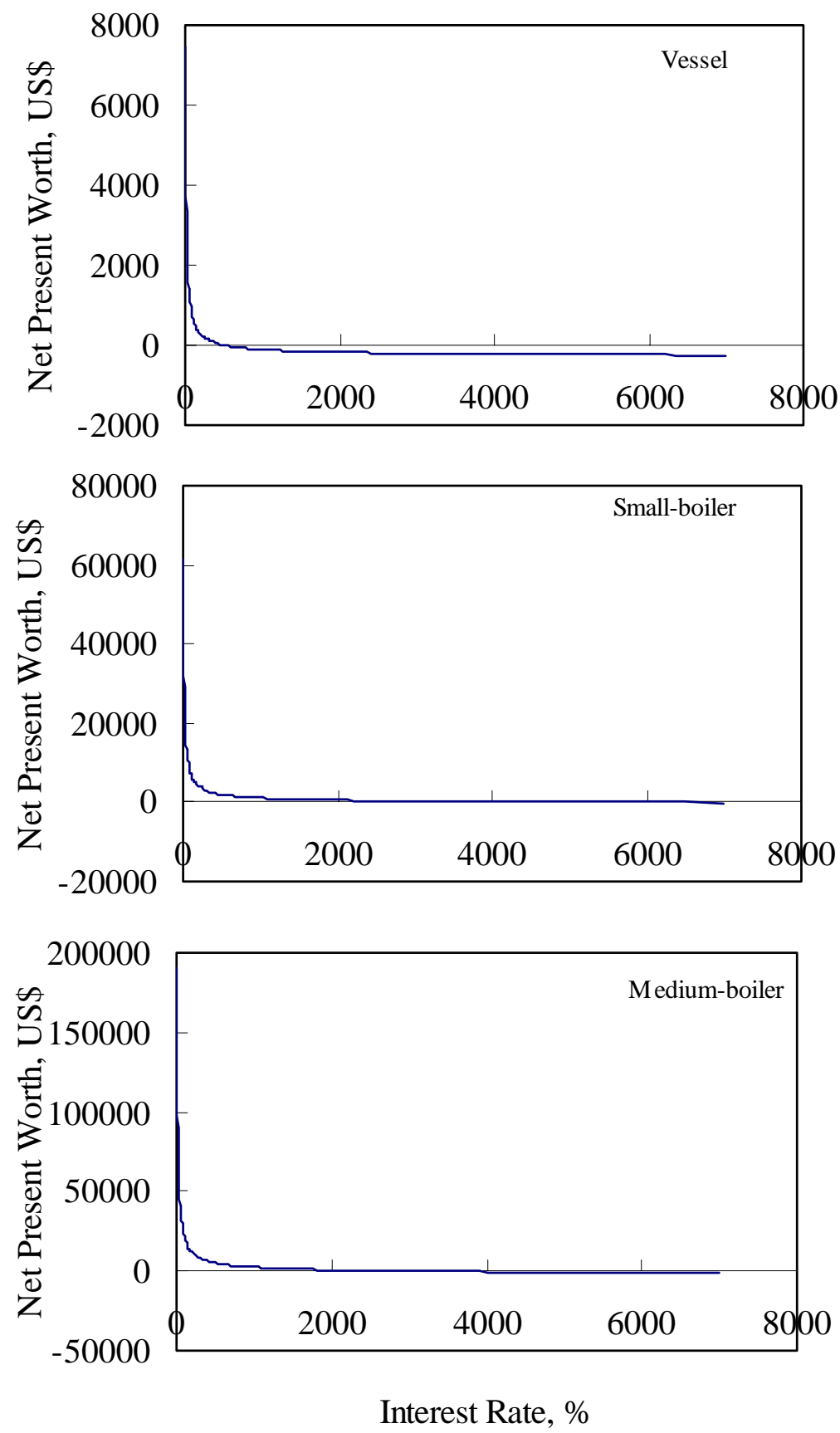

Fig. 10 Relationship between interest rate and the NPW of future income 
Table 1 Treatments time and parboiling capacity

\begin{tabular}{|c|c|c|c|c|c|c|c|}
\hline \multirow[t]{2}{*}{ Process } & \multicolumn{2}{|c|}{$\begin{array}{l}\text { No. of persons } \\
\text { involved }\end{array}$} & \multicolumn{2}{|c|}{$\begin{array}{l}\text { Initial firing, } \\
\text { min }\end{array}$} & \multicolumn{2}{|c|}{$\begin{array}{l}\text { Av. treatment } \\
\text { time/tally, min }\end{array}$} & \multirow[t]{2}{*}{$\begin{array}{c}\text { Capacity/ person/ } \\
\text { batch, kg }\end{array}$} \\
\hline & Male & Female & PS & $S$ & PS & $\mathrm{S}$ & \\
\hline Vessel & 2 & 3 & 0 & 0 & 16.1 & 17.0 & 203.6 \\
\hline Small boiler & $2(2)$ & 6 & 27.5 & 26.9 & 8.4 & 11.9 & 245.3 \\
\hline Medium boiler & $23(4)$ & - & 82.1 & 123.8 & 6.1 & 6.3 & 380.5 \\
\hline
\end{tabular}

Note: PS = Pre-steaming, $S=$ Steaming, number in the parenthesis indicates the owners of the process and are not involved in parboiling treatment 
Table 2 Energy consumption in the parboiling processes

\begin{tabular}{lccc}
\hline \multirow{2}{*}{ Process } & \multicolumn{2}{c}{ Biomass consumption, kg/t } & \multirow{2}{*}{$\begin{array}{c}\text { Total energy } \\
\text { consumption, MJ/t }\end{array}$} \\
\cline { 2 - 3 } & Pre-steaming & Steaming & 2583 \\
Vessel & 71.9 & 113.7 & 2758 \\
Small Boiler & 87.2 & 109.6 & 1659 \\
Medium Boiler & 43.1 & 75.1 & \\
\hline
\end{tabular}

Note: Heating value of rice husk $=14000 \mathrm{~kJ} / \mathrm{kg}$ (Source: FAO) 
Table 3 Installation costs of the parboiling plants (US\$)

\begin{tabular}{|c|c|c|c|c|c|c|c|c|c|c|c|}
\hline \multirow[t]{2}{*}{ Process } & \multicolumn{3}{|c|}{ Vessel or Boiler } & \multicolumn{3}{|c|}{ Hopper } & \multicolumn{2}{|c|}{ Soaking Tank } & \multicolumn{2}{|c|}{ Tube-well } & \multirow{2}{*}{$\begin{array}{l}\text { Total } \\
\text { Initial } \\
\text { Cost }\end{array}$} \\
\hline & $\begin{array}{l}\text { Cost/ } \\
\text { Unit }\end{array}$ & $\begin{array}{l}\text { Used } \\
\text { Units }\end{array}$ & $\begin{array}{l}\text { Life } \\
\text { Year }\end{array}$ & $\begin{array}{l}\text { Cost/ } \\
\text { Unit }\end{array}$ & $\begin{array}{l}\text { Units } \\
\text { used }\end{array}$ & $\begin{array}{l}\text { Life, } \\
\text { Year }\end{array}$ & Cost & $\begin{array}{l}\text { Life, } \\
\text { Year }\end{array}$ & Cost & $\begin{array}{l}\text { Life, } \\
\text { Year }\end{array}$ & \\
\hline Vessel & 5.32 & 2 & 0.5 & - & - & - & 42.55 & 10 & 21.28 & 10 & 74.47 \\
\hline Small Boiler & 42.55 & 1 & 1.0 & 42.55 & 2 & 10 & 148.94 & 10 & 21.28 & 10 & 297.87 \\
\hline Medium Boiler & 1170.21 & 1 & 1.0 & 63.83 & 4 & 10 & 638.29 & 10 & 212.77 & 10 & 2276.59 \\
\hline
\end{tabular}


Table 4 Cost of labor for parboiling, milling and the market price of paddy, parboiled rice and rice husk (US\$)

\begin{tabular}{lcccccc}
\hline \multirow{2}{*}{ Process } & \multicolumn{2}{c}{ Cost/100 kg } & & \multicolumn{3}{c}{ Market Value/100 kg } \\
\cline { 2 - 3 } \cline { 5 - 7 } & Labor & Milling & & Paddy & Rice & Husk \\
\hline Vessel & - & 0.47 & & 9.36 & 15.16 & 2.02 \\
Small Boiler & 0.27 & 0.47 & & 9.36 & 15.74 & 2.02 \\
Medium Boiler & 0.27 & 0.47 & & 9.41 & 15.74 & 2.02 \\
\hline
\end{tabular}

Note: Labor cost was not considered in the vessel process because the owners do the parboiling themselves. 